\title{
FAKTOR-FAKTOR PSIKOLOGIS WISATAWAN MANCANEGARA DALAM BERWISATA SEPEDA DI KAWASAN PANTAI SANUR BALI
}

\author{
Ni Komang Widiastri ${ }^{1}$, I Ketut Suwena ${ }^{2}$, L.G.L.K Dewi ${ }^{3}$ \\ ${ }^{1}$ Email : komangwidi01.kw@gmail.com \\ Program Studi S1 Industri Perjalanan Wisata, Fakultas Pariwisata, Universitas Udayana \\ ${ }^{2}$ Email : suwenaketut31@gmail.com \\ Program Studi S1 Industri Perjalanan Wisata, Fakultas Pariwisata, Universitas Udayana \\ ${ }^{3}$ Email : leli_ipw@unud.ac.id \\ Program Studi S1 Industri Perjalanan Wisata, Fakultas Pariwisata, Universitas Udayana
}

\begin{abstract}
Bali has a variety of tourist products and attractions that are very interesting. One of the tourism products offered by tour operators in Bali is bicycle tours in Sanur Beach Area. Consumer behavior is a process that is closely related to the buying process. This study aims to analyze the psychological factors of foreign tourists on bicycle tours in the Sanur Beach area of Bali. These psychological factors are divided into three factors, namely motivation factors, perception factors and attitude factors. Respondents used were foreign tourists who were on a bicycle trip on Sanur Beach. Total respondents were 120 people determined by non purposive sampling technique. Data analysis used quantitative descriptive analysis techniques with Likert scale and data processing through validity, reliability and factor analysis tests supported by SPSS version 17.0 for Windows. The results show that the psychological factors of tourists in bicycle tours consist of three factors, namely motivation factors, perception factors and attitude factors. And each factor has an indicator. Based on factor analysis, it was found that there were two psychological factors that influenced the decision of foreign tourists on bicycle tours in Sanur Beach with a loading factor of 60,127\%. The first factor was named the previous experience factor with a value of 7.215 and the second factor was named the family encouragement factor with a value of 1,063 based on these two factors, the dominant factor is the previous experience factor with an eigenvalue of 7,215 and has a variance percentage value of $60,127 \%$ with these results it is advisable for bike rental parties in Sanur Beach to pay more attention to bicycle rental prices to foreign tourists.
\end{abstract}

Abstrak: Bali memiliki berbagai produk wisata dan daya tarik wisata yang sangat menarik. Salah satu produk wisata yang ditawarkan oleh para pelaku usaha wisata di Bali adalah wisata sepeda di Kawasan Pantai Sanur. Perilaku konsumen merupakan suatu proses yang berkaitan erat dengan proses pembelian. Penelitian ini bertujuan untuk menganalisis faktorfaktor psikologis wisatawan mancanegara dalam berwisata sepeda di kawasan Pantai Sanur Bali. Faktor-faktor psikologis tersebut terbagi menjadi tiga faktor, yaitu faktor motivasi, faktor persepsi dan faktor sikap. Responden yang digunakan adalah wisatawan mancanegara yang sedang berwisata sepeda di Pantai Sanur. Total responden berjumlah 120 orang ditentukan dengan teknik non purposive sampling. Analisis data menggunakan teknik analisis deskriptif kuantitatif dengan skala likert dan pengolahan data melalui uji validitas, uji reliabilitas dan analisis faktor yang didukung dengan program SPSS versi 17.0 for windows. Hasil menunjukan bahwa faktor-faktor psikologis wisatawan dalam berwisata sepeda terdiri dari tiga faktor, yaitu faktor motivasi, faktor persepsi dan faktor sikap. Dan masing-masing faktor memiliki indikator. Berdasarkan analisis faktor diperoleh hasil bahwa terdapat dua faktor psikologis yang mempengaruhi keputusan wisatawan mancanegara dalam berwisata sepeda di Pantai Sanur dengan nilai loading factor sebesar $60.127 \%$. Faktor pertama diberi 
nama faktor pengalaman terdahulu dengan nilai 7.215 dan faktor kedua diberi nama faktor dorongan keluarga dengan nilai 1.063 berdasarkan kedua faktor tersebut, faktor yang dominan adalah faktor pengalaman terdahulu dengan nilai eigenvalue 7.215 dan memiliki nilai persentase variance sebesar $60.127 \%$ dengan hasil ini disarankan untuk pihak rental sepeda yang ada di Pantai Sanur agar lebih memperhatikan harga sewa sepeda kepada wisatawan mancanegara.

Keywords: psychological factors, tourist, bicycle tour.

\section{PENDAHULUAN}

Salah satu daerah di Indonesia yang pariwisatanya sangat terkenal di dunia adalah Bali. Bali merupakan provinsi yang begitu gencar mengembangkan pariwisata. Bali sudah tidak dapat dipisahkan lagi dengan pariwisata sejak beberapa abad terakhir (Sukardika, 2004 :64). Tidak hanya kebudayaan dan panorama alam, masyarakat Bali juga dikenal ramah terhadap pendatang, khususnya kepada wisatawan. Wisatawan yang datang ke Bali berasal dari berbagai penjuru dunia baik domestik maupun internasional. Sudah tidak asing lagi terdengar bahwa Bali menjadi salah satu daerah tujuan wisata idaman di dunia, terkenal akan warisan budaya, keseniannya, keramahan penduduknya serta keindahan alamnya. Saat ini kunjungan wisatawan ke Bali mengalami peningkatan. Bali memiliki berbagai produk wisata dan daya tarik wisata yang sangat menarik, mulai dari budaya, alam, bahari dan kuliner. Beragam produk wisata yang ditawarkan oleh para pelaku usaha wisata di Bali, membuat para wisatawan tertarik berkunjung ke Bali.

Sebagai pelaku pariwisata harus memahami perilaku konsumen yang berkunjung ke Bali. Perilaku konsumen merupakan suatu proses yang berkaitan erat dengan proses pembelian. Pada saat itu, konsumen melakukan aktifitasaktifitas seperti melakukan pencarian, penelitian dan pengevaluasian produk. Perilaku konsumen merupakan hal-hal yang mendasari konsumen untuk membuat keputusan pembelian. Dalam perilaku konsumen, tersirat kualitas produk yang meliputi harga produk atau jasa. Apabila harga suatu produk tidak terlalu tinggi, maka konsumen tidak akan terlalu lama membutuhkan waktu untuk memikirkan dan melakukan aktifitas perilaku konsumen. Menurut Schiffman dan Kanuk (2007), perilaku konsumen adalah suatu proses yang dilalui oleh seorang pembeli dalam mencari, membeli, mengevaluasi serta bertindak pada konsumsi produk dan jasa, maupun ide yang diharapkan dapat memenuhi kebutuhan seseorang tersebut.

Keputusan pembelian adalah tindakan yang dilakukan konsumen untuk melakukan pembelian sebuah produk. Oleh karena itu, pengambilan keputusan pembelian merupakan proses pemilihan salah satu dari beberapa alternatif penyelesaian masalah dengan tindak lanjut yang nyata. Setelah itu, konsumen mengevaluasi pilihan dan kemudian dapat menentukan sikap yang akan diambil. Selanjutnya, Engel (1994) mengatakan bahwa proses pengambilan keputusan membeli mengacu pada tindakan konsisten dan bijaksana yang harus dilakukan untuk memenuhi kebutuhan. Pada tahap proses pengambilan keputusan pembelian terdapat faktor-faktor utama yang mempengaruhi keputusan pembelian konsumen yaitu faktor budaya, faktor sosial, faktor pribadi, dan faktor psikologis.

Menurut Wundt (dalam Devidof, 1981) psikologi merupakan ilmu tentang kesadaran manusia (the science of human consciousness). Batasan ini dapat dikemukakan bahwa dalam psikologi, keadaan jiwa direfleksikan dalam kesadaran manusia. Unsur kesadaran merupakan hal yang dipelajari dalam 
psikologi. Psikologi wisatawan perlu diketahui oleh pengelola daya tarik wisata. Hal ini dikarenakan daya tarik wisata mulai berkembang semakin ketat, sehingga pengelola daya tarik wisata akan mencari konsumen sebanyak-banyaknya dan mempertahankan konsumen yang dimiliki agar terus loyal terhadap daya tarik wisata tersebut. Guna mendukung hal tersebut, pengelola daya tarik wisata perlu memahami dan mempelajari perilaku konsumen terlebih dahulu agar dapat memahami bagaimana karakteristik konsumen yang sesungguhnya. Melalui perilaku konsumen dapat diketahui tentang apa yang menjadi kebutuhan konsumen. Alasan konsumen memutuskan untuk melakukan pembelian, serta faktor-faktor apa yang mempengaruhi konsumen didalam memutuskan atau melakukan pembelian. Salah satu faktor yang sangat penting dalam perilaku konsumen adalah faktor psikologis. Faktor ini dapat mempengaruhi konsumen dalam memutuskan atau melakukan pembelian.

Suatu pengelola daya tarik wisata harus memperhatikan dan memperlakukan konsumen dengan baik agar pelanggan merasa puas dengan produk atau jasa yang dibeli maka pengelola daya tarik wisata harus memahami faktor psikologis konsumennya melalui aktivitas, minat dan pendapat dari konsumen. Dengan memahami faktor psikologis wisatawan maka akan dapat diketahui kebutuhan dan keinginan para wisatawan, sehingga baik pemerintah ataupun pelaku usaha wisata dapat meningkatkan pelayanan dan fasilitas seperti yang diharapkan para wisatawan dalam upaya memenuhi kebutuhan.

Pengelola daya tarik wisata yang memahami faktor psikologis konsumennya adalah pengelola Pantai Sanur. Pantai Sanur merupakan salah satu daya tarik wisata yang terkenal, baik pada tingkat nasional maupun tingkat internasional. Pantai Sanur terletak di Desa Sanur, Kecamatan Denpasar Selatan, Kotamadya Dati II Denpasar. Pantai ini terletak di sebelah Timur dan Selatan desa Sanur, merupakan tepi Samudra Indonesia sebelah Selatan Pulau Bali. Pantai Sanur juga dikenal sebagai pantai matahari terbit (Sunrise beach). Karena lokasinya berada di sebelah Timur pulau Bali, maka di pantai ini menjadi lokasi yang tepat untuk menikmati matahari terbit (sunrise). Hal ini membuat tempat ini makin menarik wisatawan, bahkan ada sebuah ruas pantai Sanur yang bernama pantai Matahari Terbit karena pemandangan saat matahari terbit sangat indah bila dilihat dari ruas tersebut. Sebagian kawasan wisata pantai ini mempunyai pasir berwarna putih yang eksotis. Keindahan alam menjadikan pantai Sanur sebagai pantai atau daya tarik wisata alam yang begitu eksotis dan terkenal.

Untuk menikmati alam yang indah terutama dengan kawasan pantai pasir putih yang membentang dari Utara ke Selatan, air laut yang tenang, sangat cocok untuk melakukan berbagai kegiatan wisata bahari, seperti menyelam, snorkeling, kano, berenang, dan menikmati sensasi keindahan matahari terbit yang muncul dari garis cakrawala ufuk Timur. Selain aktivitas wisata bahari, pantai ini juga menyediakan aktivitas bersepeda sepanjangan pantai di Sanur. Menurut Lumsdon (2000), Pariwisata bersepeda adalah sebuah aktivitas rekreasi menggunakan sepeda dalam satu hari atau beberapa hari, untuk tujuan jarak panjang dalam berlibur. Pantai Sanur memiliki jalur khusus bagi wisatawan yang melakukan wisata bersepeda. Hal ini membuat pantai Sanur menjadi salah satu daya tarik wisata yang unik dan favorit di mata wisatawan. Rute perjalanan wisata sepeda berjarak $4 \mathrm{~km}$, dimulai dari ruas pantai matahari terbit menuju Pantai Bali Beach, Pantai Segara Ayu, Pantai Sindhu, Pantai Karang, Pantai Semawang sampai ke Pantai Mertasari. Jika wisatawan kembali pada titik ruas pantai awal, berarti jarak yang ditempuh mencapai $8 \mathrm{~km}$.

Sepeda merupakan salah satu moda transportasi yang ramah lingkungan. 
Transportasi ramah lingkungan berarti kumpulan dari bentuk transportasi dengan model yang lebih berkelanjutan (Widiantono, 2009) menuju perkembangan lingkungan yang dapat diterima oleh masyarakat perkotaan sekaligus dapat meningkatkan produktivitas dan keuntungan dari penerapan model tersebut (Dillon, Irvine, Palmer, \& Widing, 2001). Seperti fenomena di Pantai Sanur, wisatawan yang berkunjung ke daya tarik wisata pantai Sanur lebih tertarik menikmati keindahan pantai dengan cara menggunakan sepeda daripada berjalan kaki. Dengan menaiki sepeda wisatawan dapat menikmati keindahan sepanjang pantai dari ruas Pantai Matahari Terbit sampai Pantai Mertasari dengan mudah dan lebih efisien dibandingkan dengan berjalan kaki. Alasan dari beberapa wisatawan yang diwawancarai secara singkat, mengatakan menggunakan sepeda karena merasa nyaman menggunakan sepeda daripada berjalan kaki dengan jarak yang panjang (sekitar $4 \mathrm{~km}$ ). Adapula berpendapat bahwa bersepeda di pinggir pantai memiliki keunikan sendiri, selain untuk berolahraga juga bisa menikmati pemandangan. Di sela-sela waktu tersebut wisatawan bisa mengabadikan momen dengan cara berfoto dan mengunggahnya ke akun sosial media. Berdasarkan uraian di atas maka peneliti ingin mengetahui faktor psikologis wisatawan mancanegara dalam berwisata sepeda di kawasan Pantai Sanur Bali. Selain itu, potensi daya tarik wisata sepeda yang dimiliki Pantai Sanur merupakan alasan pelengkap penelitian ini perlu dilakukan. Peneliti mengangkat judul "Faktor-faktor Psikologis Wisatawan Mancanegara Dalam Berwisata Sepeda di Kawasan Pantai Sanur Bali".

\section{METODE}

Pengumpulan data dilakukan di kawasan Pantai yang ada di Sanur. Pantai Sanur terletak di Desa Sanur, Kecamatan Denpasar Selatan Kota Madya Dati II Denpasar. Variabel dalam dibagi menjadi tiga faktor, yakni faktor motivasi, faktor persepsi, dan faktor sikap. Teknik pengumpulan data dilakukan dengan observasi, kuesioner, wawancara, studi kepustakaan, dan dokumentasi. Teknik pengambilan sampel dilakukan dengan purposive sampling. Pengumpulan data dilakukan dengan penyebaran kuesioner terhadap 120 responden. Teknik Analisis data dilakukan dengan uji validitas, uji reliabilitas, dan analisis faktor.

\section{HASIL DAN PEMBAHASAN}

Daya tarik wisata Pantai Sanur merupakan pantai yang bersejarah karena pantai ini merupakan tempat mendaratnya pasukan kerajaan Belanda ketika Belanda menyerang wilayah Badung pada waktu zaman penjajahan. Dikalangan pariwisata, pantai Sanur pertama kali diperkenalkan oleh pelukis Belgia bernama A.J. Le Mayeur bersama istrinya Ni Polok yang menetap di Sanur sejak tahun 1937. Dengan didirikannya Museum Le Mayeur, sekitar 80 lukisan dipamerkan dalam museum ini yang dulunya merupakan rumah dari artis terkenal Adrian-Jean Le Mayeur sendiri. Museum ini terletak beberapa meter dari laut adalah bukti fisik untuk cinta seorang seniman terhadap pulau Bali. Melalui lukisan spektakuler dan pameran Le Mayeur, Sanur diperkenalkan kepada dunia. Berdasarkan dokumen yang ada, baru tercatat sejak tahun 1909-1932 pertama kalinya diperintah oleh kepala desa. Kemudian dari tahun 1932-1935 terjadi pergantian kepala desa dengan wilayah Sanur meliputi daerah Sanur (Desa Sanur Kaja, Desa Sanur Kauh, Kelurahan Sanur) dan Kelurahan Renon sekarang. Sejak 1959 Sanur dikembangkan menjadi daerah wisata. Pada tahun 1963 geliat pariwisata Sanur semakin terasa dengan didirikannya Hotel Bali Beach (sekarang Inna The Grand Bali Beach). Sampai sekarang kawasan ini masih menjadi salah satu tujuan wisata utama di Kota Denpasar.

Terdapat dua faktor psikologis wisatawan mancanegara dalam berwisata sepeda di kawasan Pantai Sanur Bali. 
Ditemukan dua faktor yang terdiri atas 11 variabel, yang memiliki pengelompokan baru. Faktor-faktor baru yang telah terbentuk diberi nama sesuai dengan variabel yang telah dikelompokan. Hal ini dapat dapat diuraikan sebagai berikut.

Faktor pertama diberi nama pengalaman terdahulu, memiliki nilai eigenvalue sebesar 7.215. Adapun faktor pengalaman terdahulu terdiri atas variabel Lingkungan, Imbalan, Ciri-ciri rangsang, Nilai dan kebutuhan individu, Pengalaman terdahulu, Komponen kognotif, Komponen afektif, dan Komponen perilaku. Faktor kedua diberi nama dorongan keluarga memiliki nilai eigenvalue sebesar 1.063. Adapun dorongan keluarga terdiri atas variabel Kebutuhan, Minat, dan Dorongan keluarga.

Mengetahui faktor psikologis wisatawan mancanegara dalam berwisata sepeda di kawasan Pantai Sanur mendapatkan hasil analisis data sebagai berikut. Terdapat dua faktor yang terbentuk dari 11 indikator pembentuk awal faktor telah memenuhi nilai minimum yang ditetapkan. Faktor yang terbentuk adalah pengalaman terdahulu dengan nilai persentase variance $60.127 \%$ dan dorongan keluarga dengan nilai persentase variance $8.860 \%$.

Adapun faktor psikologis yang paling dominan dalam berwisata sepeda di kawasan Pantai Sanur dapat dilihat dalam analisis faktor yaitu sebesar 7.215. Faktor ini terdiri atas delapan indikator pembentuk yaitu: (1) Lingkungan, (2) Imbalan, (3) Ciri-ciri Rangsang, (4) Nilai dan Kebutuhan Individu, (5) Pengalaman terdahulu, (6) Komponen Kognotif, (7) Komponen Afektif, (8) Komponen Perilaku.

Faktor pengalaman terdahulu, mengungguli faktor lain. Hal ini menunjukkan bahwa faktor psikologis wisatawan mancanegara dalam berwisata sepeda di kawasan Pantai Sanur adalah dengan bersepeda dapat menghemat waktu untuk mengunjungi tujuh titik tepi pantai yang ada di Sanur, dan menggunakan sepeda sebagai pilihan kendaraan yang tepat untuk menikmati keindahan di Pantai Sanur, bersepeda di Pantai Sanur dapat menghilangkan stress serta dapat menjaga kebugaran tubuh, dan Pantai Sanur memiliki lingkungan yang bersih dan sehat yang cocok untuk wisatawan yang ingin bersepeda.

Hasil ini dikuatkan dengan wawancara yang dilakukan peneliti pada saat menyebarkan kuisioner kepada wisatawan mancanegara yang menggunakan sepeda di kawasan Pantai Sanur. Hasilnya bahwa wisatawan mancanegara yang menggunakan sepeda karena lingkungan pantai yang bersih dan sepeda adalah pilihan kendaraan yang cocok untuk menikmati keindahan pantai di Sanur. Hal tersebut membuat wisatawan mancanegara merasa nyaman dan ingin menghabiskan waktu yang lama saat berada di Pantai Sanur.

\section{SIMPULAN DAN SARAN Simpulan}

Analisis data dan pembahasan faktorfaktor psikologis wisatawan mancanegara dalam berwisata sepeda di kawasan Pantai Sanur, maka dapat diambil simpulan sebagai berikut. Terdapat dua faktor yang mempengaruhi keputusan wisatawan dalam berwisata sepeda di kawasan Pantai Sanur. Faktor pertama yaitu Pengalaman Terdahulu terdiri atas : (1) Lingkungan, (2) Imbalan, (3) Ciri-ciri rangsang, (4) Nilai dan kebutuhan individu, (5) Pengalaman terdahulu, (6) Komponen kognotif, (7) Komponen afektif, (8) Komponen perilaku. Faktor kedua yaitu Dorongan Keluarga, terdiri atas : (1) Kebutuhan, (2) Minat, (3) Dorongan Keluarga.

Faktor yang paling dominan wisatawan mancanegara dalam berwisata sepeda di kawasan Pantai Sanur Bali berdasarkan nilai eigenvalue tertinggi dalam analisis faktor yaitu sebesar 7.215. Nilai tersebut maka yang menjadi faktor paling dominan adalah faktor pengalaman terdahulu, faktor ini terdiri atas Lingkungan, Imbalan, Ciri-ciri rangsang, 
Jurnal IPTA

Nilai dan kebutuhan individu, Pengalaman terdahulu, Komponen kognotif, Komponen afektif, Komponen perilaku.

\section{Saran}

Sampai saat ini jalan setapak di sepanjang pantai dirasa belum memadai untuk wisata sepeda. Maka saran yang dapat diberikan untuk wisata sepeda yang berada di pantai Sanur yaitu dengan penataan kembali atau re-design pada jalan setapak di sepanjang pantai sebagai pembatas antara wisatawan pengguna sepeda dengan wisatawan pejalan kaki. Dan selain itu juga melengkapi fasilitas pendukung lainnya, seperti membuat zona parkir khusus untuk sepeda-sepeda yang tidak sedang digunakan. Harga sewa sepeda yang di tawarkan perlu disesuaikan dengan durasi waktu sewa dan merek sepeda yang digunakan.

Membuat akun sosial media sebagai saran promosi agar wisata sepeda di Pantai Sanur semakin dikenal wisatawan mancanegara. Akun sosial media ini bisa berisikan konten testimoni wisatawanwisatawan yang sudah pernah berwisata sepeda di Pantai Sanur. 


\section{Kepustakaan}

Anonim, 2009. Undang-Undang Republik Indonesia Nomor 10 Tahun 2009 Tentang Kepariwisataan.

Danarjati dkk. 2013. Pengantar Psikologi Umum. Yogyakarta: Graha Ilmu.

Davidoff, Linda. L terjemahan Mari Juniati. 1988. Psikologi Suatu Pengantar. Jakarta:Erlangga.

Deci, E.L, \& Ryan, R.M. 2000. The "What" and "Why" of Goal Pursuits :

Departement of Health Government of South Australia., 2002. Population Research and Outcome Studies.

Dillon, S., Irvine, N., Palmer, C., \& Widing, K. (2001). Cycling France. Oakland: Lonely Planet Publications.

James F. Engel (1994), pengertian perilaku konsumen, dalam buku Perilaku Konsumen, Edisi 6 : jilid 1. Penerbit Binarupa Aksara.

Page, S. dan Lumsdon L. (2004). Tourism and Transport: Issues and Agenda for the New Millennium. Elsevier: Boston.

Ritchie, J.R.B., Crouch G.I. (2005) The Competitive Destination: A Sustainable Tourism Perspective, CABI, Wallingford.

Sangaji, Etta Mamang, Dan Sopiah.2014. Perilaku Konsumen (Yogyakarta, Andi Offset) Setiadi, Nugroho J.2003. Perilaku Konsumen. Kencana. Jakarta.
Schiffman dan Kanuk. 2007. Perilaku Konsumen. Edisi Kedua. Jakarta: PT Indeks Gramedia

Setiadi, Nugroho J. 2010. Perilaku Konsumen. Cetakan 4. Edisi Revisi. Jakarta : Kencana

Shaleh, Abdul Rahman. 2009. Psikologi Suatu Pengantar, Jakarta :Kencana

Sugiyono. (2013). Metode Penelitian Kuantitatif, Kualitatif dan R\&D. Bandung: Alfabeta.CV

Sukardi. 2004. Metodologi Penelitian Pendidikan: Kompetensi dan Praktiknya, Jakarta: Bumi Aksara.

Suryani, Tatik. 2012. Perilaku Konsumen: Implikasi Pada Strategi Pemasaran. Graha Ilmu. Yogyakarta

Suwena, I Ketut dan I Gst Ngr Widyatmaja. 2017. Pengetahuan Dasar Ilmu Pariwisata. Denpasar : Pustaka Larasan

Widiantono, Joni J. (2009). Green Transport: Upaya Mewujudkan Transportasi 